\title{
COMPARISON OF SOME SPRAYING SYSTEMS IN VINEYARDS
}

\author{
W. F. T. HARTILL
}

Plant Diseases Division, DSIR, Auckland

\section{Summary}

Sprays applied with conventional air-blast sprayers were well distributed on vine foliage. Applications made with two other types of tractor-drawn sprayer - one using ducted fans, the other using motorised spinning cages - and with a helicopter fitted with spinning cages, were less well distributed, but the cover obtained was generally adequate. When a helicopter fitted with a 60-nozzle boom was used the cover obtained was not adequate. In vineyards receiving two consecutive helicopter sprays a combination of applications along and across the rows gave better cover than applications made in only one direction.

\section{INTRODUCTION}

Grape growers follow a comprehensive spray schedule and typically use air-blast sprayers of the 'Metters', 'Holder', 'Platz', etc. type. The volume applied is usually either 'Dilute' $(2,000-3,000$ litres/ha) or ' $x 3$ Concentrate' (670-1,000 litres/ha). Mixing and applying these volumes in normal commercial vineyards is time consuming and some growers have been investigating the potential of alternative, lower-volume, application systems. I have co-operated in some of these investigations on an ad hoc basis. Two alternatives were investigated: tractor-drawn low- to mediumvolume sprayers and application by helicopter.

\section{METHODS}

Tracer. 'Saturn Yellow', a fluorescent tracer, was added to the spray mixture at a fixed rate of $670 \mathrm{~g} / \mathrm{ha}$ irrespective of the volume being applied. The tracer plus Tween $20(12.5 \mathrm{ml} / \mathrm{ha})$ was pre-mixed with a small quantity of water in a blender to form a slurry that could be diluted rapidly in the spray tank.

Sprayers

(i) Tractor-drawn $(3.2 \mathrm{~km} / \mathrm{h} ; 450$ litres/ha):

'Metters A.F.2', 4 nozzles/side

'Span Spray', 5 hydraulically-driven spinning cages/row of vines.

'Kinkelder', ducted air-blast

(ii) Helicopter (two passes along each row in opposite directions):

'Micronair' wind-driven spinning cages (4 rows/swathe, $72 \mathrm{~km} / \mathrm{h}$ )

Te Kauwhata trial used 4 cages/boom, 150 litres/ha

Taupaki trials used 6 cages/boom, 170 litres/ha

60-nozzle boom Spraying Systems' 45 whorl plates, D8 discs) 5 rows! swathe, $40 \mathrm{~km} / \mathrm{h}, 150$ litres/ha

(Metters A.F.2, 4 nozzles/side, 840 litres/ha $3.2 \mathrm{~km} / \mathrm{h}$ used in comparison).

Proc. 29th N.Z. Weed and Pest Control Conf. 
Assessments. After the spray had dried, 20-30 leaves were taken at random from the top and sides of, and from inside, the vine canopy, packed separately between sheets of paper, and taken to a dark room. The deposits were viewed under short-range ultra-violet light, scored for density on an arbitrary scale, and the results converted to a percentage index. It was also possible to obtain from these scores the proportion of leaves where the deposit was evenly distributed and the proportion with a negligible deposit.

\section{RESULTS}

(i) Tractor-drawn sprayers

The densest and most even cover was provided by the Metters sprayer (Table 1). However, this was used at below the planned spetd and the tracer application exceeded $670 \mathrm{~g} / \mathrm{ha}$ and a strict comparison with the other machines was not possible. The Kinkelder gave a similar cover to that provided by the Metters sprayer on the upper surface of the leaf but an inferior cover on the lower surface. The Span Spray applied a similar cover to both leaf surfaces, inferior to that obtained with the other two sprayers on the upper surface, but similar to that obtained with the Kinkelder on the lower surfaces. When the Span Spray was used there was considerable drift.

TABLE 1: SPRAY COVERAGE ON GRAPE FOLIAGE, MEASURED BY FLUORESCENT TRACER, OBTAINED WITH TRACTOR-DRAWN SPRAYERS

\begin{tabular}{|c|c|c|c|c|}
\hline \multirow[t]{2}{*}{ Sprayer } & \multicolumn{2}{|c|}{ Mean cover index ${ }^{*}$} & \multicolumn{2}{|c|}{$\%$ of leaves with even cover } \\
\hline & Upper surface & Lower & Upper surface & Lower \\
\hline Metters A.F.2 & 95 & 97 & 88 & 88 \\
\hline Span-Spray & 79 & 78 & 67 & 70 \\
\hline Kinkelder & 94 & 73 & 96 & 63 \\
\hline
\end{tabular}

${ }^{*} 0=$ no deposit

$100=$ heavy, even cover; droplets starting to coalesce

(ii) Helicopter sprays

The cover obtained from helicopter sprays was compared with that obtained from a Metters A.F.2 sprayer. The Metters sprayer provided an even cover on most parts of the plant examined: no misses were found (Table 2). Helicopter applied sprays provided a poorer deposit distribution, particularly on the under surfaces. When the helicopter was used, a boom with four Micronair units provided better spray distribution than one with 60 conventional nozzles. Leaves from dense clusters of foliage sprayed by the latter system frequently had little or no tracer deposit on them. Similar results were obtained when these three techniques were compared again, with the number of Micronair units increased to six per boom.

TABLE 2: SPRAY COVERAGE ON GRAPE FOLIAGE MEASURED BY FLUORESCENT TRACER, OBTAINED FROM APPLICATIONS MADE BY TRACTOR AND BY HELICOPTER

\begin{tabular}{|c|c|c|c|c|}
\hline \multirow[t]{2}{*}{ Sprayer } & \multicolumn{2}{|c|}{ Mean cover index ${ }^{\star}$} & \multicolumn{2}{|c|}{$\%$ of leaves with even cover } \\
\hline & surface & Lower & Upper surface & Lower \\
\hline $\begin{array}{l}\text { Tractor (Metters A.F.2) } \\
\text { Helicopter }\end{array}$ & 94 & 91 & 98 & 95 \\
\hline $\begin{array}{l}\text { (4x Micronair cages) } \\
\text { Helicopter }\end{array}$ & 79 & 45 & 70 & 29 \\
\hline (60-nozzle boom) & 75 & 37 & 61 & 23 \\
\hline
\end{tabular}

${ }^{\star} 0=$ no deposit

$100=$ heavy, even cover; droplets starting to coalesce 


\section{Application Techniques}

The effect of the direction of spray application was examined in another trial, using a helicopter fitted with six Micronair units. Sprays applied along or at right angles to the rows were less evenly and less densely deposited than sprays applied alternately from both directions (Table 3). In this trial the sprays were applied in a strong breeze and the deposits tended to be light on downwind leaves.

TABLE 3: SPRAY DEPOSITS ON GRAPE FOLIAGE, MEASURED BY FLUORESCENT TRACER, AFTER A SERIES OF DOUBLE PASSES WITH A HELICOPTER FITTED WITH SIX MICRONAIR CAGES

\begin{tabular}{lccccc}
\hline Direction of pass & \multicolumn{2}{c}{$\begin{array}{c}\text { Mean cover index } \\
\text { Upper surface }\end{array}$} & Lower & \multicolumn{2}{c}{$\begin{array}{c}\text { \% of leaves with even cover } \\
\text { Upper surface }\end{array}$} \\
\hline $\begin{array}{l}\text { Both across the row } \\
\text { (opposite directions) }\end{array}$ & 61 & 40 & 40 & 41 \\
$\begin{array}{c}\text { Both along the row } \\
\text { (opposite directions) }\end{array}$ & 56 & 47 & 48 & 48 \\
$\begin{array}{c}\text { Alternately along } \\
\text { and across the row }\end{array}$ & 74 & 53 & 61 & 42 \\
\hline
\end{tabular}

${ }^{*} 0=$ no deposit

$100=$ heavy, even cover; droplets starting to coalesce

\section{DISCUSSION}

Although conventional air-blast sprayers appeared to give the best cover in these trials, all but one of the other systems tested - the helicopter fitted with a 60-nozzle boom - gave what was probably an effective cover on most leaves. These alternative systems apply a smaller spray volume than conventional air-blast sprayers but the droplet size spectrum is also reduced. Leaves therefore tend to be covered with distinct droplets containing a relatively concentrated pesticide suspension, whereas leaves sprayed with conventional equipment frequently appear to have been washed in dilute pesticide. Pesticides used in vineyards are normally re-distributed across and between leaves through the action of dew and light rain, so that only spraying systems which leave significant gaps in pesticide coverage can be considered ineffective on the evidence of tracer studies. Further testing should therefore be carried out to examine the levels of disease and pest control obtained with these systems when a full season's spray schedule has been applied.

Some commercial spraying of vineyards by helicopter was carried out following these tests. However, there was a tendency to reduce costs by reducing the number of sprays, and disease control was generally poor. Kinkelder and Span Spray units are now in operation in commercial vineyards. 